\title{
Nontemporal effect of ITI on discriminated one-way avoidance responding
}

\author{
HEIDAR A. MODARESI \\ University of California, Riverside, California 92502
}

\begin{abstract}
Three groups of hooded rats were exposed to a safe platform for different proportions of the ITI duration, in a signaled 1-way avoidance experiment. The rats with longer safe-platform exposure performed better than the ones with less exposure. These results are consistent with Denny's (1971) relaxation theory of avoidance learning.
\end{abstract}

It is a well established finding that discriminated oneand two-way (directional) avoidance learning is an increasing function of duration of the intertrial interval (ITID), at least up to 5 min (Boice, 1970; Bolles \& Grossen, 1970; Brush, 1962; Kurtz \& Shafer, 1967; Levine \& England, 1960). The functional relationship between directional avoidance learning and the ITID, moreover, seems to be much like that between a positively reinforced operant and its contingent reinforcer (Denny \& Weisman, 1961). On the basis of the assumption that ITI's reinforce avoidance responding, the ITID may be said to be a measure of the reinforcement magnitude.

There are also indications that ITIs can be functionally differentiated in terms of a nontemporal dimension. Specifically, given a constant ITID, the rate of directional avoidance learning seems to vary along the gradient of stimulus similarity between the shock compartment and the compartment used to confine the subject during ITIs. Learning is markedly improved when the latter compartment is distinctively different from the shock compartment (Reynierse \& Rizley, 1970), the rate of learning being directly related to the length of confinement in the distinctive ITI compartment (Potts \& McKown, 1969; Tenen, 1966). In these latter experiments, for example, different groups of rats were trained to avoid a footshock by jumping onto a safe and distinctive platform. Subjects were gently pushed back onto the grid floor after they had spent prescribed durations on the platform. The results clearly indicated that subjects with longer platform exposure duration showed better learning.

These findings, unfortunately, can at best provide an inconclusive support for the present view of nontemporal aspect of the ITI; in both these experiments, the effect of platform exposure time was invariably confounded with the facilitatory effect of the ITID in that a longer platform exposure resulted also in a longer ITID.

The present study is an attempt to isolate the effect of a nontemporal aspect of ITI (i.e., platform exposure

\footnotetext{
This paper is sponsored by Austin Riesen who takes full editorial responsibility for it.
}

during ITI) from that of its temporal aspect (i.e., ITID), in a modified one-way apparatus.

\section{METHOD}

\section{Subjects and Apparatus}

Subjects were 18 naive adult male hooded rats approximately 120 days of age. The apparatus consisted, basically, of a wooden box, $53 \times 23 \times 23 \mathrm{~cm}$ high (inside dimensions) with a Plexiglas top and a grid floor. At one end was located a horizontal platform made of Plexiglas, $1.27 \mathrm{~cm}$ above the grid floor. The platform formed a $23 \times 23 \mathrm{~cm}$ surface at one end of the apparatus. The end walls consisted of two movable partitions which could be slid along the side walls from one end to the other end. Only the end wall on one side of the platform (Wall P) was used. The other wall was stationary at all times. The shock intensity was about $.8 \mathrm{~mA}$ at $310 \mathrm{~V}$. The warning signal (WS) consisted of the movement of Wall $P$ and simultaneous illumination of one of the $2.5 \mathrm{~W}$ lights under a milky Plexiglas cover located below the grid floor, exactly half-way between the two end walls. The other light was continuously on.

\section{Procedure}

The subject was placed on the platform and left undisturbed for $30 \mathrm{sec}$. Following this period, Wall $P$ was slowly moved toward the other end wall, thus pushing the subject off the platform, until Wall $P$ reached within $20 \mathrm{~cm}$ of the other end wall. The subject was then left undisturbed in the resultant $20 \times 23 \times 23 \mathrm{~cm}$ high compartment for $30 \mathrm{sec}$ following which experiment proper began; the warning light was turned on and, simultaneously, Wall $\mathbf{P}$ was moved back over the platform toward its original position at the platform end of the box until the platform was completely exposed. Shock followed $5 \mathrm{sec}$ later. Running response onto the safe platform during the WS prevented the shock onset and terminated the WS. The same response during shock terminated both shock and the WS. Three randomly selected groups of six rats each were differentiated in terms of proportion of the 35-sec ITID they were allowed to be on the safe platform; Groups 30,15 , and 5 spent, respectively, 30,15 , and $5 \mathrm{sec}$ of the ITID on the platform. Following the appropriate exposure duration to the platform, subjects were pushed back very gently by Wall $P$ (Wall $P$ displacement time $=$ $8 \mathrm{sec}$ ) off the platform onto the grid floor and were left there unmolested for the rest of the ITID. The next trial began following the ITID. All subjects were run in random order in a single 30-trial session.

\section{RESULTS AND DISCUSSION}

The results are presented in Figure 1 in terms of mean 


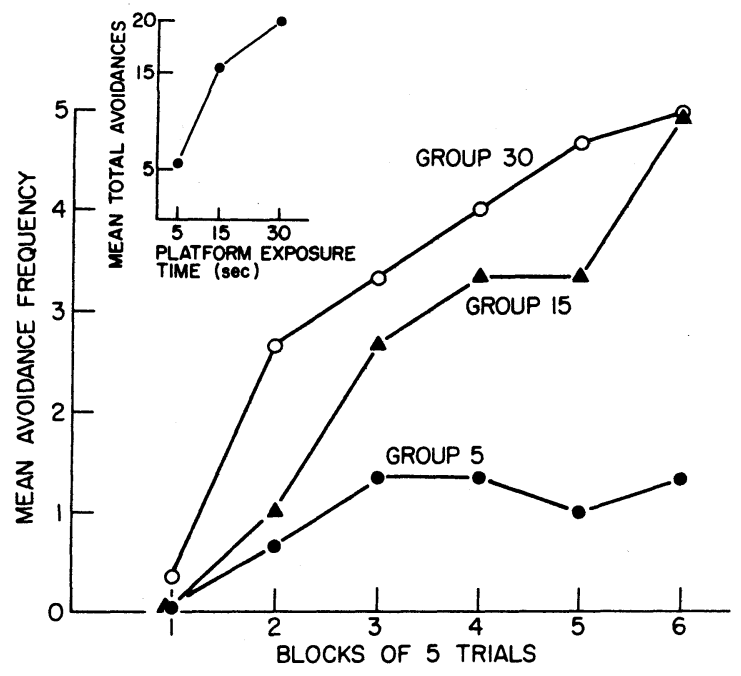

Figure 1. Mean avoidance frequency in blocks of five trials. The left-hand side insert represents the mean total avoidances as a function of the platform exposure time.

avoidance frequency in blocks of five trials, and in the left side insert of the same figure, in terms of the mean total avoidance as a function of the platform exposure time. A one-way analysis of variance on the latter measure indicated a significant main effect $(\mathrm{p}<.05)$. Group 30 was reliably superior to Group $5(\mathrm{t}=3.53$, df $=10, \mathrm{p}<.01$ ) while not significantly different from Group 15. Superiority of Group 15 over Group 5 was also statistically reliable $(\mathrm{t}=3.87, \mathrm{df}=10, \mathrm{p}<.005)$.

These results are completely consistent with those of Potts and McKown (1969) and Tenen (1966). Avoidance responding in the present study was deteriorated when a greater proportion of the ITID was spent in the shockbox. Alternatively, with greater platform exposure time, avoidance responding was enhanced along a negatively accelerated function (see the insert in Figure 1). Thus although the temporal aspect of ITI, i.e., ITID, was identical for all subjects, the ITI seemed to be more reinforcing, that is, resulted in better learning, when a greater proportion of it was associated with a safe platform.

These results bear strong resemblance to those reported when a positive reinforcement is varied along a quantitative (Logan, 1960) or a qualitative (Hutt, 1954) dimension. To this extent, the priciples of positive reinforcement may be generalized to the case of avoidance responding. The results could also shed some light on the underlying factors responsible for commonly reported difficulties in training the rat to learn discriminated barpress avoidance responding; in addition to the unnatural topography of barpressing response (Bolles, 1970; Meyer, Cho, \& Weseman, 1960) an inadequate reinforcement may also be involved.

Finally, the present results are in complete harmony with the relaxation theory of avoidance learning (Denny, 1971). Subjects' relaxation responses may be, accordingly, said to develop faster, or to a greater extent, when the safe period, i.e., the ITI, is spent in a relatively less aversive environment.

\section{REFERENCES}

Boice, R. Effect of domestication on avoidance learning in the Norway rat. Psychonomic Society, 1970, 18, 13-14.

Bolles, R. C. Species-specific defense reactions and avoidance learning. Psychological Review, 1970, 77, 32-48.

Brush, F. R. The effect of intertrial interval in avoidance learning in the rat. Journal of Comparative and Physiological Psychology, 1962, 55, 888-892.

Denny, M. R. Relaxation theory and experiments. In F. R. Brush (Ed.), Aversive conditioning and learning. New York: Academic Press, 1971.

Denny, M. R., \& Weisman, R. G. Avoidance behavior as a function of length of nonshock confinement. Journal of Comparative and Physiological Psychology, 1961, 58, 252-257.

Hutt, P. J. Rate of bar pressing as a function of quality and quantity of food reward. Journal of Comparative and Physiological Psychology, 1954, 47, 235-239.

Kurtz, P. J., \& Shafer, J. N. The interaction of UCS intensity and intertrial interval in avoidance learning in the rat. Psychonomic Science, 1967, 8, 465-466.

Levine, S. \& England, S. J. Temporal factors in avoidance learning. Journal of Comparative and Physiological Psychology, 1960, 58, 282-283.

Logan, F. A. Incentive. New Haven, Connecticut: University Press, Yale: 1960.

Meyer, D. R., Cho, C., \& Weseman, A. F. On problems of conditioning discriminated lever-ress avoidance responses. Psychological Review, 67, 224-228.

Potts, W. J. \& McKown, Jr. Effects of platform exposure duration on acquisition performance in an automated one-way avoidance procedure. Psychological Report, 1969, 24, 959-964.

Reynierse, J. H., \& Rizley, R. C. Relaxation and fear as determinants of maintained avoidance in rats. Journal of Comparative and Physiological Psychology, 1970, 72, 223-232.

Tenen, S. An automated one-way avoidance box for the rat. Psychonomic Science, 1966, 24, 959-963.

(Received for publication October 15, 1974.) 